\title{
Tribute to a pioneer: Viking Olov Björk, 1918-2009
}

Francis Robicsek, MD, PhD

In 1947 I demonstrated the possibilities for openheart surgery on dogs by means of a heart-lung machine with a spinning disc oxygenator, with the aid of a volume-regulated Engstrom respirator, evolved for the use in poliomyelitis. I was the first to introduce postoperative intensive care for cases with bilateral pulmonary or severe heart disease. In the course of lung surgery I conceived the technique of complete left-sided heart catheterization. I then systematically worked on cases of heart valve disease, and in 1969 introduced an improved artificial heart valve. Various congenital malformations presented major challenges for me to understand and surgically correct. My wife Ingegerd, a chemical engineer, has through all these years given tremendous help and support in my work....

These are the introductory words to the autobiography of the great Scandinavian surgeon Viking Björk.

Björk was one of the last living pioneers of cardiothoracic surgery. He was born on December 3, 1918, in Sunnansjö, Sweden, and received his medical education at three different Swedish universities: Lund, Uppsala, and Malmö. In 1942, Björk worked as a fellow in Italy under Vincenzo Monaldi, studying tuberculosis. His scientific report, "The Treatment Of Tuberculotic Lung Cavities According to Monaldi,' became the first of several hundred of his publications in the field of pulmonary and cardiac surgery.

After his return from Italy, Björk worked as a fellow at the University Hospital in Lund, where he conducted research on the prevention of pulmonary embolism. A year later, he was granted a British Council scholarship at the Brompton Hospital in London, where he was exposed to the activities of several leading English cardiothoracic surgeons, including Belsey and Brock. He also had the opportunity to meet Dwight Harken, who presented a lecture on removal of metallic foreign bodies from the hearts of 100 soldiers.

The encounter that was probably the most important in his lifetime was that with Clarence Crafoord, the leading Swedish surgeon of his time. In 1946, at the meeting of the Royal College of Surgeons, Crafoord gave a lecture on the first case of successful aortic resection for coarctation. Crafoord, who

\footnotetext{
From the Carolinas Heart Institute, Carolinas Medical Center, Charlotte, NC.

Received for publication March 24, 2009; accepted for publication March 24, 2009. Address for reprints: Francis Robicsek, MD, PhD, The Carolinas Heart Institute, Carolinas Medical Center, Department of Thoracic/Cardiovascular Surgery, 1001 Blythe Blvd, Suite 300, Charlotte, NC 28203 (E-mail: theresa.r.johnson@ carolinashealthcare.org)

J Thorac Cardiovasc Surg 2009;137:1309-10

$0022-5223 / \$ 36.00$

Copyright (c) 2009 by The American Association for Thoracic Surgery doi:10.1016/j.jtcvs.2009.03.029
}

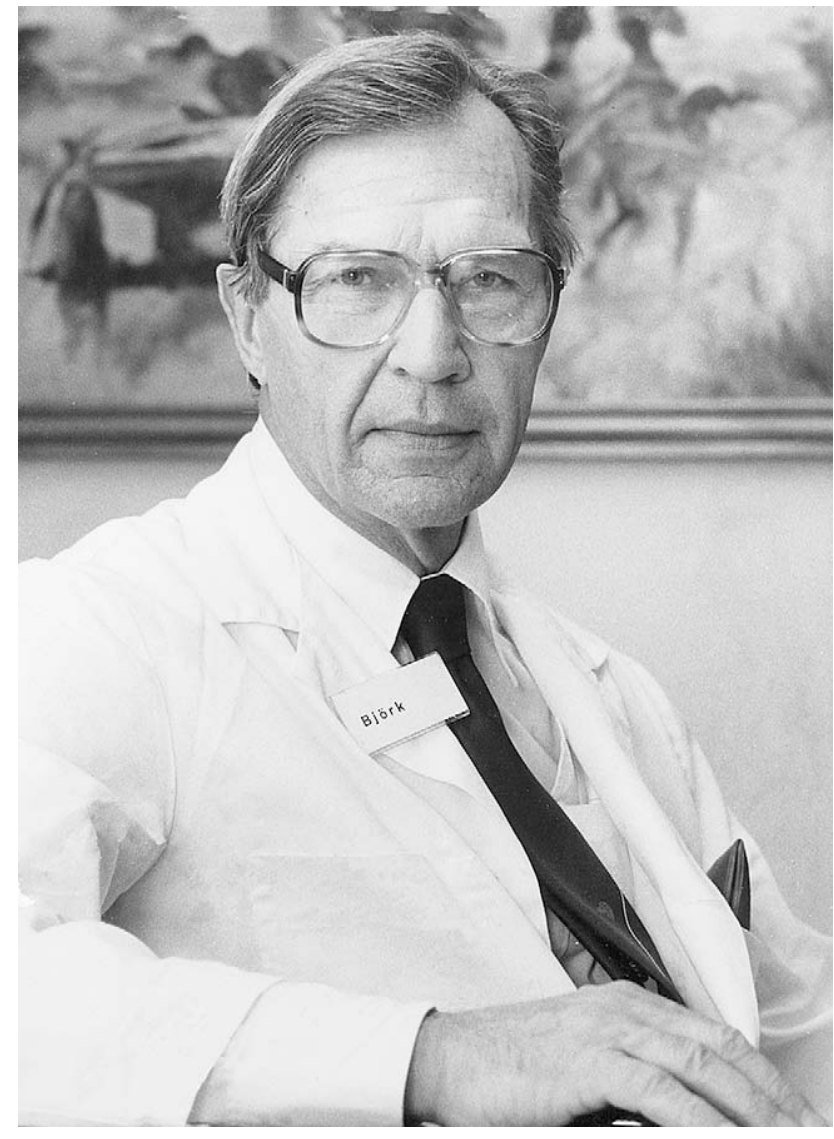

FIGURE 1. Dr Viking Olov Björk, 1918-2009.

was extremely interested in the subject of extracorporeal circulation, invited Björk to work at his laboratory at the Sabbatsberg Hospital in Stockholm, Sweden. Together with Emil Anderson, a mechanical engineer with the AGA Company, Björk constructed a disc-oxygenator and eventually wrote his doctoral thesis on the subject. In 1950, Björk received a grant from the Swedish-American Foundation and sailed to the United States, where he spent time with such leading cardiac American surgeons as Blalock, Harken, Gerbode, and Holman. On his return to Sabbatsberg, Björk continued his work in both pulmonary and cardiac surgery. His attention, however, soon concentrated on the heart. His bold percutaneous catheter approach to the left heart led to the first successful open-heart operation in Europe, when Crafoord, using Björk's heart-lung machine, removed a left atrial myxoma diagnosed by Björk, an historic operation that I, as Björk's guest, was also allowed to witness.

In the upcoming years, Björk worked as assistant professor in charge of research activities at the newly organized 
Cardiac Clinic on the grounds of the Karolinska Institute in Stockholm. He also traveled extensively in Europe, the United States, Japan, and the Soviet Union, lecturing and demonstrating. His travels also gave him an opportunity to establish connections and forge friendships with leading cardiologists and cardiac surgeons of his time. In 1958, Björk was named as the Head of the Cardiothoracic Department of Uppsala University. He was relentless and multifaceted; his activities included not only improving the AGA-Björk heart-lung machine but also perfecting his method of leftheart catheterization, and he teamed up with the famous French surgeon Charles Dubost to explore the limitations of deep hypothermia and circulatory arrest. His method of bicuspidalization of the incompetent aortic valve is now experiencing a revival in modern cardiac surgery. Björk was among the first in Europe to use a mechanical heart valve, an interest that accompanied him throughout his lifetime and led to the development of the Björk-Shiley low-profile prosthetic valve. In 1966, he succeeded Crafoord as professor of surgery at the Karolinska, where the facilities were much better. His honors were numerous. He was elected to honorary memberships of several prestigious professional societies, including the American Association of Thoracic Surgery and the Royal College of Surgeons. He became the president of the Scandinavian and later the European
Society of Thoracic and Cardiovascular Surgery. He was the editor of the Scandinavian Journal of Thoracic Surgery.

Björk remained at the helm of Karolinska's heart program for the next 14 years. During this period, his activities extended to virtually all aspects of heart surgery. He developed new methods to repair complex congenital anomalies, invented the pericardial insulation pad, and spent considerable efforts to modify and improve his prosthetic valve. In 1983, at the age of 65, Björk retired from his post at Karolinska. He continued to be active as a teaching surgeon at different institutions, however, primarily in Italy. Björk's professional "last stand" was directorship of the Eisenhower Medical Center in Rancho Mirage, California, where he investigated the possibility of developing a mechanical heart valve that would not require anticoagulation.

In his retirement, Björk spent most of his time with his wife, Ingegerd, on his family estate in northern Sweden. He remained a gracious host to his old friends. On February 18,2009 , at the age of 90, Björk died in Stockholm of internal hemorrhage sustained in a subway accident. He is survived by his wife, three children, and nine grandchildren.

Viking Björk, the leading personality of Scandinavian cardiac surgery, made an everlasting mark in the history of cardiothoracic Surgery as a master surgeon, teacher, inventor, and visionary of "things to come." 